\title{
Evaluation of Endodontic Productivity in Oral Public Healthcare Services in Minas
}

\section{Gerais, Brazil}

Avaliação da Produtividade em Endodontia em Serviços de Saúde Pública Bucal em Minas Gerais, Brasil

Evaluación de la Productividad Endodóntica en Servicios de Salud Pública Oral en Minas Gerais, Brasil

\begin{abstract}
The aim of this study was to evaluate the factors associated with the average monthly productivity in endodontic services at Dental Specialty Centers (DSCs) of Minas Gerais. Secondary data were collected: the dependent variable was the average monthly productivity in endodontic services at DSCs, and the independent variables: population size, Human Development Index (HDI), Gini Index, Family Health Program's (FHP) population coverage rate, DSC type, and accreditation time. 76 DSCs were included. Median values for population size, HDI, Gini Index, FHP coverage, and accreditation service time were, respectively, 67,442.50, 0.732, 0.410, 77.945, and 8.00. The endodontic treatment of single-rooted teeth exhibited the highest median production. Most of the DSCs $(61.7 \%)$ did not reach the targets set. Population size $(\mathrm{p}=0.001)$ and DSC type $(\mathrm{p}=0.025)$ were associated with the average monthly productivity. The average monthly productivity in endodontic services at these DSCs was low, which was positively associated with population size and accredited DSC type.
\end{abstract}

Keywords: Health services research; Dental health services; Secondary care; Endodontics.

\section{Resumo}

O objetivo deste estudo foi avaliar os fatores associados à produtividade média mensal em serviços de endodontia em Centros de Especialidades Odontológicas (CEOs) de Minas Gerais. Foram coletados dados secundários: a variável dependente foi a produtividade média mensal em serviços de endodôntia nos CEOs, e as variáveis independentes: tamanho da população, Índice de Desenvolvimento Humano (IDH), Índice de Gini, taxa de cobertura populacional do Programa Saúde da Família (PSF), tipo de CEO e tempo de credenciamento. 76 DSCs foram incluídos. Os valores medianos para tamanho da população, IDH, Índice de Gini, cobertura do PSF e tempo de credenciamento do serviço foram, respectivamente, $67.442,50 ; 0,732 ; 0,410 ; 77,945$ e 8,00. O tratamento endodôntico de dentes unirradiculares exibiu a maior produção mediana. A maioria dos CEOs $(61,7 \%)$ não atingiu as metas estabelecidas. O tamanho populacional $(\mathrm{p}=0,001)$ e o tipo de DSC $(\mathrm{p}=0,025)$ estiveram associados à produtividade média mensal. A produtividade média mensal em serviços endodônticos nesses CEOs foi baixa, o que se associou positivamente ao tamanho da população e ao tipo de CEO credenciado.

Palavras-chave: Pesquisa sobre serviços de saúde; Serviços de saúde bucal; Atenção secundária à saúde; Endodontia. 


\section{Resumen}

El objetivo de este estudio fue evaluar los factores asociados a la productividad promedio mensual en los servicios de endodoncia en los Centros de Especialidades Dentales (CDS) de Minas Gerais. Se recolectaron datos secundarios: la variable dependiente fue la productividad promedio mensual en los servicios de endodoncia en los CSD, y las variables independientes: tamaño de la población, Índice de Desarrollo Humano (IDH), Índice de Gini, Tasa de cobertura poblacional del Programa de Salud de la Familia (PSF), tipo de CDS, y tiempo de acreditación. Se incluyeron 76 DSC. Los valores medios para el tamaño de la población, el IDH, el índice de Gini, la cobertura de PSF y el tiempo de servicio de acreditación fueron, respectivamente, 67,442.50, 0,732, 0,410, 77,945 y 8,00. El tratamiento de endodoncia de dientes unirradiculares exhibió la producción mediana más alta. La mayoría de los CAD $(61,7 \%)$ no alcanzó los objetivos establecidos. El tamaño de la población $(\mathrm{p}=0,001)$ y el tipo de DSC $(\mathrm{p}=0,025)$ se asociaron con la productividad mensual promedio. La productividad mensual promedio en los servicios de endodoncia en estos DSC fue baja, lo que se asoció positivamente con el tamaño de la población y el tipo de DSC acreditado.

Palabras clave: Investigación sobre servicios de salud; Servicios de salud dental; Atención secundaria de salud; Endodoncia.

\section{Introduction}

The Brazilian Unified Health System (SUS in Portuguese) was established to ensure access to healthcare services for the population. The incorporation of oral health collective procedures was an important transformation from an individualisticcurative to a collective-preventive stance (Pucca Jr. et al., 2009).

The inclusion of oral health teams within of the Family Health Program (FHP), today called Family Health Strategy, was regulated in 2000, for the reorganization of primary healthcare (Pucca Jr. et al., 2009). In 2004, the Brazilian Ministry of Health (MofH) launched the Oral Health National Policy ("Smiling Brazil"), which resulted in a long process of the institutionalization of dentistry within SUS (Brazil, 2004).

This policy implemented secondary oral care by chosen Dental Specialty Centers (DSCs) (Brazil, 2004). The DSCs are based on the epidemiological population profile and offer specialized services in an attempt to solve a deficit in dental care of a population who suffer from oral diseases in a wide range of specialties, including periodontics, endodontics, dental care for patients with special needs, oral diagnosis, and minor oral surgery (Pedrazzi et al., 2008). DSCs are regionally distributed in Brazilian municipalities and are integrated within local and regional planning processes (Pedrazzi et al., 2008; Pucca Jr. et al., 2009). They seek to increase access to oral healthcare with a more complete view of the health-disease process, to incorporate medium and high complexity procedures and services, and to articulate intersectional activities (Brazil, 2004).

These DSCs can contribute to the building of a healthcare network, defined as a set of articulated actions and health services, at increasingly complex levels with different technological densities to ensure the integrality of healthcare. This strategy improves health, reduces the incidence of disease, and contributes to reducing inequality (Brazil, 2011). Many countries in Latin America have promoted the development of these networks to provide a coordinated continuum of services to a defined population (Vázquez et al., 2015).

Regarding physical-structural features, DSCs are classified into three types: I (three dental chairs), II (4 to 6 dental chairs), or III (more than 7 dental chairs). DSCs must work 40 hours per week, but the number of professionals by specialty is variable and depends on the epidemiological needs of the population of each city where the service is implemented (Pedrazzi et al., 2008).

MofH defines the types of procedures that may be performed for each specialty in the DSCs. For the endodontic area, the list of procedures, although this list does not cover all endodontic procedures, includes: endodontic treatment and retreatment of single-rooted, biradicular, and multiradicular teeth; endodontic treatment of primary teeth; and sealing of root perforation (Brazil, 2011). MofH indicates minimum productivity targets for different types of DSCs to monitor the performance of these centers. The minimum monthly production requirement in endodontic services is 35 , 60 , and 95 
procedures per month for DSC types I, II, and III, respectively. Moreover, mandatorily, 20.0\% of the total productivity must include endodontic treatment and/or retreatment of multiradicular teeth (Brazil, 2006).

The evaluation of health services and monitoring the results of dental care are essential tools in public health and contribute to the production of useful measures that aid in decision-making (Reeve et al., 2015). Until recently, the evaluation of secondary oral care provided by public services in Brazil was very difficult (Machado et al., 2008), and specific assessment of a single specialty, such as endodontics, on the secondary oral care services is scarce in the literature, especially in the state of Minas Gerais (MG). MG is located in the southeast of Brazil, represents the third most important economic region of the country, and is the second most populous Brazilian state, with 19,597,330 inhabitants (IBGE, 2010) distributed in 853 municipalities.

Recently, political decisions increased the allocation of resources and ensured the growth of the healthcare network (Lino et al., 2014). Thus, evaluations of DSCs are appropriate to improve processes and actions to increase the performance of these services (Cortellazzi et al., 2014). Mainly to endodontics, that is the most in demand specialized service in the DSCs in Brazil, once the teeth pain is one of the main reasons for seeking oral healthcare (Pinto et al., 2022).

This cross-sectional study aimed to evaluate the factors associated with the average monthly productivity in endodontic services of DSCs in MG, considering municipal socio-demographic indicators and structural variables of services.

\section{Methods}

All DSCs in MG accredited at MofH until December 2013 that were in operation and with endodontic productivity available in 2014, according to the database of the MG State Health Department and the Department of Informatics of SUS (DATASUS in Portuguese) were included in the study.

Secondary data of the endodontic output for each DSC were collected in 2015 according to the National Register of Health Institutions (CNES in Portuguese) from SUS's Outpatient Information System, using the DATASUS system. Tabbing was performed using the Tab for Windows Program (TABWIN Program) of the MofH by a single researcher who was trained to work with these databases. This system only shows the output per month without noting the number of professionals who worked to achieve these results.

The dependent variable was defined as the average monthly productivity in endodontic services at DSCs in 2014. The fulfillment or non-fulfillment of the productivity targets was determined by examining the monthly productivity data of the months available for analysis for each DSC, considering the rules set forth by the MofH (Brazil, 2006).

The independent variables included city and service characteristics. City characteristics - population size (dichotomized by median in: $<67,442.50$ and $\geq 67,442.50$ ), Human Development Index (HDI) (dichotomized by median in: $<0.732$ and $\geq 0.732$ ), and Gini Index (dichotomized by median in: $<0.410$ and $\geq 0.410$ ) - were collected from the Brazilian Institute of Geography and Statistics website (IBGE in Portuguese) (IBGE, 2010).

Service characteristics included the FHP's population coverage rate, obtained from the MofH website (Brazil, 2014) (dichotomized by median in: < 77.945 and $\geq 77.945$ ); type of DSC (I, II, or III); and accreditation time (dichotomized by median in: $<8.0$ and $\geq 8.0$ ), obtained from the MG State Health Department's database (Minas Gerais, 2014).

This methodology was guided by the study of Figueiredo and Goes (2009), but with the necessary adjustments, considering our dependent and independent variables.

Data were analyzed using IBM SPSS Statistics for Windows, version 22.0 (IBM Corp., Armonk, NY, USA). Descriptive statistics were obtained for all variables. The Kolmogorov-Smirnov test was used to determine the distribution of 
the data. Analysis by Pearson's chi-square $\left(\chi^{2}\right)$ test was conducted for the association between the dependent variable (average monthly productivity) and independent variables. The confidence level was set at $95 \%$.

The Human Research Ethics Committee at Universidade Federal de Minas Gerais (UFMG) approved, in 2014, this evaluative study (logged under protocol number: CAAE- 34771514.0.00005149).

\section{Results}

In 2014, there were 92 accredited and operating DSCs in 85 municipalities of MG. The selection criteria of this study revealed 76 eligible DSCs ( $82.6 \%$ of the sample) in 70 municipalities ( $8.2 \%$ of the State's municipalities). Sixteen DSCs were eliminated for the following reasons: seven were accredited after December 2013, eight were not listed in the DATASUS database in 2014, and one was de-accredited by MofH in 2014.

Table 1 shows the descriptive analysis of the characteristics of the analyzed cities and services, as well as the output of endodontic procedures performed by DSCs in MG in 2014. The results demonstrated that the median value for population size, HDI, Gini Index, FHP coverage, and accreditation service time was, respectively, 67,442.50, 0.732, 0.410, 77.945, and 8.00. Evaluations of the output of endodontic procedures revealed a greater median production for endodontic treatments of single-rooted teeth, followed by multiradicular and biradicular teeth. A lower production was observed for endodontic retreatments and the sealing of perforations.

Table 1 - Characteristics of the analyzed cities and services, and output of endodontic procedures $(n=76)$ in MG, Brazil, in 2014.

\begin{tabular}{|c|c|c|c|c|c|}
\hline Variables & Median & $\mathbf{P 2 5}$ & P75 & Minimum & Maximum \\
\hline \multicolumn{6}{|l|}{ Cities and service characteristics } \\
\hline Population size & $67,442.50$ & $32,405.50$ & $149,003.75$ & $5,287.00$ & $2,375,151.00$ \\
\hline HDI & 0.732 & 0.702 & 0.765 & 0.604 & 0.813 \\
\hline Gini Index & 0.410 & 0.400 & 0.430 & 0.330 & 0.480 \\
\hline Coverage FHP (\%) & 77.945 & 57.208 & 97.880 & 18.210 & 100.000 \\
\hline Accreditation service time (years) & 8.00 & 6.00 & 8.00 & 1.00 & 9.00 \\
\hline \multicolumn{6}{|l|}{ Output of endodontic procedures } \\
\hline Endodontic retreatment of single-rooted teeth & 1.00 & 0.00 & 5.00 & 0.00 & 216.00 \\
\hline Endodontic retreatment of biradicular teeth & 0.00 & 0.00 & 2.00 & 0.00 & 106.00 \\
\hline Endodontic retreatment of multiradicular teeth & 0.00 & 0.00 & 2.00 & 0.00 & 119.00 \\
\hline Endodontic treatment of primary teeth & 16.00 & 0.00 & 54.50 & 0.00 & 600.00 \\
\hline Endodontic treatment of single-rooted teeth & 144.00 & 88.75 & 249.00 & 0.00 & $1,405.00$ \\
\hline Endodontic treatment of biradicular teeth & 83,50 & 51,75 & 143,50 & 0.00 & 1154.00 \\
\hline Endodontic treatment of multiradicular teeth & 128.00 & 50.25 & 211.75 & 0.00 & $1,806.00$ \\
\hline Sealing of root perforation & 0.00 & 0.00 & 1.00 & 0.00 & 1.00 \\
\hline
\end{tabular}


The descriptive analyses of the service characteristics revealed 23 type I DSCs (30.3\%), 50 type II DSCs (65.8\%), and only 3 type III DSCs (3.9\%). Fifty-one DSCs (67.1\%) did not reach the MofH productivity targets of the months available for analysis.

Table 2 shows the associations between average monthly productivity (dependent variable) of the analyzed DSCs and the independent variables. It was found that population size $(\mathrm{p}=0.001)$ and DSC type $(\mathrm{p}=0.025)$ were significantly associated with the average monthly productivity.

Table 2 - Analysis by $\chi^{2}$ test for the association between the dependent variable (average monthly productivity) and independent variables.

\begin{tabular}{|c|c|c|c|c|}
\hline \multirow[t]{2}{*}{ Variables } & \multicolumn{2}{|c|}{ Average monthly productivity } & \multirow[t]{2}{*}{$\chi^{2}$ test } & \multirow[t]{2}{*}{ p value } \\
\hline & $\begin{array}{c}<40.4250 \\
\mathrm{n}(\%)\end{array}$ & $\begin{array}{c}\geq 40.4250 \\
\text { n (\%) }\end{array}$ & & \\
\hline \multicolumn{5}{|l|}{ Population size } \\
\hline$<67,442.50$ & $26(68.4 \%)$ & $12(31.6 \%)$ & 10.316 & $0.001^{*}$ \\
\hline$\geq 67,442.50$ & $12(31.6 \%)$ & $26(68.4 \%)$ & & \\
\hline \multicolumn{5}{|l|}{ HDI } \\
\hline$<0.732$ & $19(51.4 \%)$ & $18(48.6 \%)$ & 0.053 & 1.000 \\
\hline$\geq 0.732$ & $19(48.7 \%)$ & $20(51.3 \%)$ & & \\
\hline \multicolumn{5}{|l|}{ Gini Index } \\
\hline$<0.410$ & $14(53.8 \%)$ & $12(46.2 \%)$ & 0.234 & 0.890 \\
\hline$\geq 0.410$ & $24(48.0 \%)$ & $26(52.0 \%)$ & & \\
\hline \multicolumn{5}{|l|}{ Coverage FHP (\%) } \\
\hline$<77.945$ & $20(52.6 \%)$ & $18(47.4 \%)$ & 0.211 & 0.646 \\
\hline$\geq 77.945$ & $18(47.4 \%)$ & $20(52.6 \%)$ & & \\
\hline \multicolumn{5}{|l|}{ DSC's type } \\
\hline type I DSC & $16(69.6 \%)$ & $07(30.4 \%)$ & 5.050 & $0.025^{\circ}$ \\
\hline type II and III DSC & $22(41.5 \%)$ & $31(58.5 \%)$ & & \\
\hline \multicolumn{5}{|c|}{ Accreditation service time (years) } \\
\hline$<8.0$ & $14(43.8 \%)$ & $18(56.3 \%)$ & 0.864 & 0.353 \\
\hline$\geq 8.0$ & $24(54.5 \%)$ & $20(45.5 \%)$ & & \\
\hline
\end{tabular}

${ }^{*}$ statistical significance $(\mathrm{p}<0.05)$. Source: Authors.

\section{Discussion}

This study demonstrated that only a small portion of the municipalities in MG contained eligible DSCs in 2014. The geographic distribution of the analyzed DSCs revealed that some health regional areas had no accredited DSCs, showing weaknesses in the state's health regionalization process. MG is divided geographically into 28 health regional managements, and four which have no accredited DSCs, which compromises the integrality of the dental care provided to the population and hinders the shaping of network assistance (Machado et al., 2015). One study (Lino et al., 2014) also found that in MG, despite its broad territory, concentrations of DSCs were found in some regions, which contrasts directly with the dental care gaps in others. Throughout Brazil, the quantity of DSCs is still growing; however, most of these DSCs are still concentrated in the most populous regions (Machado et al., 2015).

The evaluated municipalities exhibited heterogeneous population sizes, which was observed due to the discrepancy between the minimum and maximum values (ranging from 5,287 inhabitants in the smallest municipality to $2,375,151$ 
inhabitants for the largest municipality), in which is in accordance with findings from a national study (Cortellazzi et al., 2014). It is important to note that there is no minimum population size for DSC implementation in Brazilian municipalities (Magalhães et al., 2012).

Descriptive studies to evaluate Brazilian secondary oral care usually involve associations between the productivities of these services with the socio-demographic factors and structural aspects of municipalities. They reveal that the productivities are generally low and below the stipulated limits of the $\mathrm{MofH}$, with the worst performances observed in small towns and lower HDI (Figueiredo \& Goes, 2009; Magalhães et al., 2012; Goes et al., 2012; Cortellazzi et al., 2014; Cabral et al., 2019). The population size correlated with the average monthly productivity, which demonstrates that the larger population size was related to greater endodontic production, which was likely due to the larger demand. Other studies have also demonstrated that a larger population size exhibited the best performance results in oral health services (Figueiredo \& Goes, 2009; Magalhães et al., 2012; Goes et al., 2012; Celeste et al., 2014; Cortellazzi et al., 2014).

The socio-economic indicators (HDI and Gini index) of the cities where the evaluated DSCs are implemented proved to be similar, since the median values of these indexes are close to their respective minimum and maximum values. HDI includes the level of education, longevity, and income, and is usually used by the United Nations for comparisons of the level of quality of life on an international basis (Roncalli et al., 2014). Gini Index measures the degree of concentration of the per capita household income distribution and is justified because the social inequalities present in the indicators of the healthdisease process imply inequalities in the patterns of diseases and use of services (Chiavegatto-Filho et al., 2012).

Positive association of the HDI of municipalities with good DSC performance rates had already been reported in the literature (Figueiredo \& Goes, 2009; Magalhães et al., 2012; Goes et al., 2012; Cortellazzi et al., 2014; Cabral et al., 2019). Cortellazzi et al. (2014) affirmed that municipalities with a low HDI and possibly, education variables and/or variables related to income, interfered in the accumulation of a population's dental needs. Therefore, although this study did not observe an association between the socio-economic indicators and the dependent variable, they are determinants in the construction of health needs of a given region. They also support the principle of equity in health, which offers more health services to those who need them most (i.e., less-favored cities), and they strive to recognize the differences in living conditions, health, and people's general needs, especially considering the fact that the right to health passes through social differentiations and therefore must provide a diversity of services (Monteiro et al., 2016).

Some studies (Aquilante e Aciole, 2015; Machado et al., 2015) assumed that greater FHP coverage favored potential access to DSCs, making use of referrals to the center and its endodontic production. However, it is necessary to examine how greater access to primary healthcare may yield better outcomes in cases that require other levels of complexity within the health system. In this study, despite the high median value for FHP coverage, which presupposes more comprehensive primary care, no association was found. Furthermore, some studies have demonstrated controversial results between the FHP coverage rate and DSC performance (Figueiredo \& Goes, 2009; Chaves et al., 2010; Goes et al., 2012; Herkrath et al., 2013; Celeste et al., 2014; Cortellazzi et al., 2014).

In this study, the median value of the accreditation service time was high, although it showed no association with the average monthly productivity. Accreditation service time may interfere in the efficiency of services, as services that are in operation for longer periods of time tend to be more efficient (Donabedian, 1973). However, other variables may influence the results of the structure, process, and outcome of these services, as advocated by Donabedian (1997). This author considered that the structural conditions of health services, which are the conditions that build and shape the universe of practices to be 
assessed (e.g., financial, human, physical, organizational resources), may favor the analysis of data in an evaluative process. Therefore, a minimum structure is necessary but is still not enough to ensure high quality care.

Most of the accredited DSCs analyzed in this study were type II, as observed in other studies (Figueiredo \& Goes, 2009; Goes et al., 2012; Cortellazzi et al., 2014, Pinto et al., 2022). The average monthly productivity positively correlated with the statistical significance with the DSC type. More complex DSCs (types II and III, with larger physical structures and greater human resources) exhibited higher productivity, which reflected its higher endodontic treatment capacity. The Donabedian model (Donabedian, 1997) to evaluate the quality of health services considers that structural conditions can favor the work processes, as they allow for the measurement of their results.

Most evaluative studies (Figueiredo \& Goes, 2009; Magalhães et al., 2012; Goes et al., 2012; Celeste et al., 2014; Cortellazzi et al., 2014; Pinto et al., 2022) of Brazilian secondary care indicate that the structural characteristics of municipalities (e.g., type of DSC and accreditation time service) influence the performance and fulfillment of targets of the DSCs. Additionally, as the number of professionals by specialty in the DSCs is variable and depends on the epidemiological needs of the local population (Pedrazzi et al., 2008), more well-structured services must contain a larger number of specialized dentists with more clinical experience, a larger quantity of dental chairs per center to perform endodontic procedures, and a greater overall number of treated patients. Cabral et al. (2019) did not find no association between the type of DSC and their performance in achieving goals. However, a recent study that evaluated the factors associated with the achievement of endodontic goals in Brazilian DSCs found that type I DSCs and type II DSCs showed 2.10 and 1.20 higher likelihood to reach the fulfillment of targets of the endodontics specialty than type III DSCs (Pinto et al., 2022).

Few services are based on the study of epidemiological factors for their implementation. As a result, DSCs often fail to meet the true health needs of a given population (Goes et al., 2012). In this light, type I DSCs should be reviewed, given that limited structures imply less services provided to the population, thus resulting in lower productivity.

The evaluation of productivity data in endodontics of the analyzed DSCs revealed a higher median value of production for the endodontic treatment of single-rooted teeth, which is in disagreement with epidemiological studies that demonstrated that molars are the most endodontically treated teeth (Bjorndal et al., 2006). These results may be explained by the need for the DSCs to achieve a minimum target that is monthly regulated by the MofH (Brazil, 2006). This target does not differentiate among the procedures to be performed, which may be considered a limitation in the study of DSC performance, since the studied data only represent the number of completed treatments (Cortellazzi et al., 2014). Furthermore, endodontic treatment of the multiradicular tooth demands more clinical hours, thus impacting the final work process and reducing the number of procedures per work shift. This fact can accumulate unmet demand for endodontic services in public health, with constant returns to primary healthcare units because of problems with the same tooth, fracture of the tooth, and even tooth extraction (Magalhães et al., 2019).

The performance assessment of each analyzed DSC for the endodontic area demonstrated that only $32.9 \%(\mathrm{n}=25)$ of the DSCs reached the MofH target of months with available production. Lino et al. (2014) highlighted a critical point of the targets set by the MofH, which is the power with which each service must direct the production of these procedures to reach these targets. The targets should differentiate less complex procedures (e.g., endodontic treatment of single-rooted teeth) from more complex procedures and the greater needs of the population, which include the endodontic treatment of multiradicular teeth (Bjorndal et al., 2006). The criteria for achieving the targets are also limited, since the targets only consider completed treatments and do not include intermediate procedures, such as ongoing treatments (Cortellazi et al., 2014). Moreover, 
complications, such as dental fracture, loss of the tooth, or treatment abandonment by the patient, may occur between endodontic treatment sessions after the pain has been relieved.

Previous studies found similar results in performance assessments, which indicates a difficulty in reaching the MofH targets (Figueiredo \& Goes, 2009; Goes et al., 2012; Lino et al., 2014; Cortellazzi et al., 2014; Pinto et al., 2022) and demonstrates the need to revise the targets and/or change the management of these services (Goes et al., 2012; Lino et al., 2014). Cortellazzi et al. (2014) found a lower target compliance rate for endodontics (22.61\%) in one evaluation at the national level in Brazil. Lino et al. (2014) demonstrated low endodontic production (16.8\%) in the evaluated DSCs of MG, and 77.0\% of the municipalities presented a zero rate of procedures for this specialty in 2010. Figueiredo and Goes (2009) found a satisfactory achievement of target for endodontics in DSCs in the state of Pernambuco, Brazil (63.6\%). However, Machado et al. (2015) justified that the evaluated DSCs were located in larger municipalities and were planned and agreed upon as landmarks targeted for large demands. These DSCs most likely have no difficulties in fulfilling the goals.

The establishment of healthcare networks allows for the proper primary/secondary interface, which is an important factor for a greater productivity of the DSCs (Brazil, 2014). This interface concerns the integration of primary and secondary healthcare as regards the supply and the rendering of services to the population (Morris \& Burke, 2001), given that an ideal interface includes access to secondary care for all cases referenced without barriers (Machado et al., 2015) and the organization of primary healthcare implies less need for secondary oral care (Azevedo et al., 2020). Martins et al. (2016) suggested certain difficulties in the relationship between primary and secondary care in specific specialties in oral health, with a large number of oral health teams (OHT) of primary care with limited access to DSCs, in addition to different performance in terms of OHT access to DSCs throughout Brazilian regions. Therefore, DSC deployment in municipalities in which primary healthcare is not properly structured is not recommended, since secondary care would be exposed to free demand and the performing of basic procedures that do not fulfill the principles required for integrality (Chave et al., 2010).

The incorporation of new technologies in specialized public healthcare (eg.: rotary instruments in endodontics) is an interesting alternative to solve low productivity problems (Sanchez \& Ciconelli, 2012), to expedite conclusions of endodontic treatments, to increase access to and reduce the waiting times for treatment by reorganizing the patient flow and work processes (Magalhães et al., 2019). One of the pillars of the quality care of Donabedian (1997) is that a good process increases the probability of good outcomes. Therefore, it is essential to develop work processes that enable the formation and operation of an oral healthcare network (Machado et al., 2015). Otherwise, a fragmented healthcare model will persist, which does not respond to the demands of the population, neither continuously nor longitudinally. According to Cabreira et al. (2022), another alternative to improve and increase the productivity by DSCs may be the pay-for-performance, which it is also used to improve access to health services.

The present study is an advance in the evaluation of secondary oral healthcare, mainly in the field of endodontics. However, some results should be interpreted with caution, as the use of secondary data may result in information bias (underor over-notifications). As the service staff itself is responsible for filling in the data in the system, municipalities may have intentionally entered the system only because the target had been reached. Furthermore, in some cases, only two months of productivity was actually reported. Hence, if the data is not filled in properly, it can be lost.

However, the use of secondary data from health information systems was consistent with the objectives of the present study and, in terms of management, helps to provide easy access to information from these systems and knowledge of information by the manager, which allows for effective health policy evaluations. Advances in the mechanisms and tools of 
monitoring and evaluation used by SUS managements, together with a greater diversification of these systems, provides a wide array of data that tend to be more fully integrated (Lino et al., 2014).

\section{Conclusions}

Finally, the evaluation of endodontic services in secondary oral care at DSCs in MG demonstrated that the average monthly productivity in the endodontic services provided by these DSCs was associated with the population size of the cities where the DSCs were in full operation and the type of duly accredited DSC. Furthermore, most of these centers have not fulfilled the productivity target set forth by the respective federal agency, which indicates that other factors may be influencing production processes and results. Thus, management measures and productivity targets must be reevaluated in order to control the release of secondary data.

The data from this study may guide other studies to evaluate other DSC specialties and contribute to the discussion of the role of DSCs in the oral healthcare network. The results revealed the need to adapt specific criteria and standards for the implementation and monitoring of these services, since a high percentage of DSCs exhibited poor performance.

Acknowledgements: The authors are grateful to the Conselho Nacional de Desenvolvimento Científico e Tecnológico (CNPq), Coordenação de Aperfeiçoamento de Pessoal de Nível Superior (CAPES), Fundação de Amparo à Pesquisa do Estado de Minas Gerais (FAPEMIG), and Pró-Reitoria de Pesquisa da Universidade Federal de Minas Gerais (PRPq-UFMG) for funding this study.

\section{References}

Aquilante, A. G. \& Aciole, G. G. (2015). Oral health care after the National Policy on Oral Health - "Smiling Brazil": a case study. Cien Saude Colet, 20(1):239-48.

Azevedo, M. B., Pinto, R. S., Abreu, M. H. N. G. \& Lucas, S. D. (2020). Factors associated with the needs of specialized dental treatment among adults aged 35-44 years old in the state of Minas Gerais, Brazil: a multilevel cross-sectional study. Ciênc Saúde Coletiva, 25(7):2783-92.

Bjorndal, L., Laustsen, M. H. \& Reit, C. (2006). Root canal treatment in Denmark is most often carried out in carious vital molar teeth and retreatments are rare. Int Endod J, 39(10):785-90.

Brazil (2011). [Decree 7508 of June 28, 2011, which regulates Law 8080 of September 19, 1990, to provide for the organization of the Universal Health System (SUS), health planning, health care, the structure among the federation and other measures]. 2011. Official Diary of the Union 2011, 28Jun.

Brazil (2015). Ministry of Health. Basic Care Department. History of Family Health coverage, 2014. https://egestorab.saude.gov.br/paginas/acessoPublico/relatorios/relHistoricoCoberturaAB.xhtml.

Brazil. Ministry of Health (2006). Ordinance No. 600 / GM of March 23, 2006. It establishes the funding of Dental Specialized Centers (DSC). Official Diary of the Union, 23Mar, 2006.

Brazil. Ministry of Health. Guidelines of the National Oral Health Policy, 2004.

Cabral, D. C. R., Flório, F. M. \& Zanin, L. (2019). Performance analysis of the specialized dental centers of the Brazilian southeast region. Cad Saúde Colet, 27(2):241-247.

Cabreira, F. D. S., Hugo, F. N. \& Celeste, R. K. (2022). Pay-for-performance and dental procedures: A longitudinal analysis of the Brazilian Program for the Improvement of Access and Quality of Dental Specialities Centres. Community Dent Oral Epidemiol, 50:4-10.

Celeste, R. K., Moura, F. R., Santos, C. P. \& Tovo, M. F. (2014). Analysis of outpatient care in Brazil municipalities with and without specialized dental clinics, 2010. Cad Saude Publica, 30(3):511-21. Text in Portuguese.

Chaves, S. C. L., Barros, S. G., Cruz, D. N., Figueiredo, A. C. L., Moura, B. L. A. \& Cangussu, M. C. T. (2010). Brazilian Oral Health Policy: factors associated with comprehensiveness in health care. Rev Saude Publica, 44(6):1005-13.

Chiavegatto-Filho, A. D. P., Lebrão, M. L. \& Kawachi, I. (2012). Income inequality and elderly self-rated health in São Paulo, Brazil. Annals of Epidemiology, 22(12):863-67. 
Cortellazzi, K. L., Balbino, E. C., Guerra, L. M., Vazquez, F. L., Bulgareli, J. V., Ambrosano, G. M. B. et al. (2014). Variables associated with the performance of Centers for Dental Specialties in Brazil. Rev Bras Epidemiol, 17(4):978-88.

Donabedian, A. (1973). Aspects of medical care administration: specifying requirements for health care. Cambridge: Harvard University.

Donabedian, A. (1997). The quality of care. How can it be assessed? Arch Pathol Lab Med, 121:1145-50.

Figueiredo, N. \& Goes, P.S.A. (2009). Development of secondary dental care: a study on specialized dental clinics in Pernambuco State, Brazil. Cad Saude Publica, 25(2):259-67. Text in Portuguese.

Goes, P. S. A., Figueiredo, N., Neves, J. C., Silveira, F. M. M., Costa, J. F. R., Pucca Júnior, G. A. et al. (2012). Evaluation of secondary care in oral health: a study of specialty clinics in Brazil. Cad. Saúde Publica, 28 Suppl:S81-S89. Text in Portuguese.

Herkrath, F. J., Herkrath, A. P. C. Q., Costa, L. N. B. S. \& Gonçalves, M. J. F. (2013). Performance of Specialized Dental Care Centers considering the sociodemographic context of municipalities of the Amazonas State (Brazil, 2009), Brasil, 2009. Saude Debate, 37(96):148-58. Text in Portuguese.

Instituto Brasileiro de Geografia e Estatística (IBGE). Censo demográfico 2010.http://www.ibge.gov.br/estadosat/perfil.php?sigla=mg.

Lino, P. A., Werneck, M. A., Lucas, S. D. \& Abreu, M. H. (2014). Analysis of secondary care in oral health in the state of Minas Gerais, Brazil. Cien Saude Colet, 19(9):3879-88. Text in Portuguese.

Machado, F. C., Silva, J. V., \& Ferreira, M. A. (2015). Factors related to the performance of Specialized Dental Care Centers. Cien Saude Colet, 20(4):114963.

Magalhães, B. G., Oliveira, R. S., Gaspar, G. S., Figueiredo, N. \& Goes, P. S. A. (2012). Avaliação do Cumprimento de Atenção Secundária em Saúde Bucal. Pesq Bras Odontoped Clin Integr, 12(1):107-12. Text in Portuguese.

Magalhães, M. B. P., Oliveira, D. V., Lima, R. F., Ferreira, E. F. \& Martins, R. C. (2019). Evaluation of secondary care in endodontics at Dental Specialties Centers (DSC). Cien Saude Colet, 24(12):4643-4653.

Martins, R.C., Reis, C.M.R., Matta Machado, A.T.G., Amaral, J.H.L., Werneck, M.A.F. \& Abreu, M.H.N.G. (2016). Relationship between Primary and Secondary Dental Care in Public Health Services in Brazil. PLoS ONE, 11(10): e0164986. DOI: 10.1371/journal.pone.0164986.

Minas Gerais (2014). State Health Department (SES/MG). Consolidated/2014 worksheet of the Dental Specialized Centers (DSC) of Minas Gerais. State Archive of Minas Gerais, in 2014.

Monteiro, C. N., Gianini, R. J., Barros, M. B., Cesar, C. L., \& Goldbaum, M. (2016). Access to medication in the Public Health System and equity: populational health surveys in São Paulo, Brazil. Rev Bras Epidemio, 19(1):26-37.

Morris, A. J. \& Burke, F. J. T. (2001). Primary and secondary dental care: the nature of the interface. Br Dent J, 191(12):660-64.

Pedrazzi, V., Dias, K. R. H. C. \& Rode, S. M. (2008). Oral health in Brazil - Part II: dental specialty centers (CEOs). Braz Oral Res, 22(Suppl 1):18-23.

Pinto, R. D. S., Lucas, S. D., Goes, P. S. A. D., Silva S. L., Neves, E. S. M., Zina, L. G. et al. (2022). Contextual and local determinants associated with the achievement of goals in the endodontics specialty in Brazilian dental speciality centres: A multilevel analysis. Community Dent Oral Epidemiol, 50:74-82.

Pucca Jr., G. A., Costa, J. F. R., Chagas, L. D. \& Sivestre, R. M. (2009). Oral health policies in Brazil. Braz Oral Res, 23 Suppl 1:9-16.

Reeve, C., Humphreys, J. \& Wakerman, J. (2015). A comprehensive health service evaluation and monitoring framework. Eval Program Plann, 53:91-8.

Roncalli, A. G., Tsakos, G., Sheiham, A., de Souza, G.C. \& Watt, R.G. (2014). Social determinants of dental treatment needs in Brazilian adults. BMC Public Health, 14:1097.

Sanchez, R. M. \& Ciconelli, R. M. (2012). The concepts of health access. Rev Panam Salud Publica, 31(3):260-68. Text in Portuguese.

Vázquez, M. L., Vargas, I., Unger, J. P., De Paepe, P., Mogollón-Pérez, A.S., Samico, I. et al. (2015). Evaluating the effectiveness of care integration strategies in different healthcare systems in Latin America: The EQUITY-LA II quasi-experimental study protocol. BMJ Open, $5(7)$ : e007037. 